\title{
Spatial heterogeneity of soil water content on surface land following reforestation in a semi-arid region
}

\author{
Junjun Yang ${ }^{1}$, Zhibin $\mathrm{He}^{2}$, Jianmin Feng ${ }^{1}$, Pengfei $\mathrm{Lin}^{3}$, Jun $\mathrm{Du}^{2}$, Lingxia Guo ${ }^{1}$, Yufeng \\ $\mathrm{Liu}^{1}$, Meng Kou ${ }^{1}$, Guohua Wang ${ }^{4}$, and Jialiang Yan $^{5}$ \\ ${ }^{1}$ Xianyang Normal University \\ ${ }^{2}$ Cold and Arid Regions Environmental and Engineering Research Institute, Chinese \\ Academy of Sciences \\ ${ }^{3}$ Northwest Institute of Eco-Environment and Resources, Chinese Academy of Sciences \\ ${ }^{4}$ Shanxi Normal University \\ ${ }^{5}$ Taiyuan Normal University
}

January 27,2022

\begin{abstract}
The spatial pattern of soil water content (SWC) determines the success of vegetation restoration in semi- and arid regions. The Qilian Mountains in China are in a semi-arid area where decades of environmental degradation prompted large-scale restoration efforts with a native constructive species Picea crassifolia. However, the relationships between SWC and landcover are not clear in this area, hindering woodland restoration. In this study, we determined spatial distribution and characteristics of SWC in the Qilian Mountains in four main types of landcover. Our results revealed that 1 . SWC decreased in the order of natural forest, brushland, grassland, planted forest, and mixed forest, but it was significantly different only in natural forest ( $\mathrm{p}<0.05$ ); 2. planted forest exhibited a lower SWC at young ages (less than 50 a) than natural forest, brushland or grassland, and the ecohydrological effect of afforestation exhibited hysteresis at long time scales; 3. a variogram analysis and Kriging interception of the spatial pattern of SWC showed that shrubland and grassland exhibited superior adaptability to local SWC compared with afforestation. The differences in SWC among various landcover types indicated that strengthening the maintenance and protection of natural forests is more important for restoration efforts than afforestation; furthermore, in semi-arid regions, shrubs and grasses are more suitable for use in ecological restoration than forest plantations.
\end{abstract}

Spatial heterogeneity of soil water content on surface land following reforestation in a semi-arid region Junjun Yang ${ }^{\mathrm{a}}$, Zhibin He ${ }^{\mathrm{b}}$ 11Corresponding author. E-mail address: junjun_yang@126.com., Jianmin Feng ${ }^{\mathrm{a}}$, Pengfei Lin ${ }^{\mathrm{b}}$, Jun Du ${ }^{\mathrm{b}}$, Lingxia Guo ${ }^{\mathrm{a}}$, Yufeng Liu ${ }^{\mathrm{a}}$, Meng Kou ${ }^{\mathrm{a}}$, Guohua Wang ${ }^{\mathrm{c}}$, , Jialiang Yan ${ }^{\mathrm{e}}$

a College of Resource \& Environment and Historical Culture, Xianyang Normal University, Xianyang 712000, China

b Linze Inland River Basin Research Station, Chinese Ecosystem Research Network, Key Laboratory of Ecohydrology of Inland River Basin, Northwest Institute of Eco-Environment and Resources, Chinese Academy of Sciences, Lanzhou 730000, China

c College of Geographical Sciences, Shanxi Normal University, Taiyuan 030000, China

d Key Laboratory of Desert and Desertification, Northwest Institute of Eco-Environment and Resources, Chinese Academy of Science, Lanzhou 730000, China

e Institute of Geography Science, Taiyuan Normal University, Jinzhong 030619, Shanxi, China 


\begin{abstract}
:
The spatial pattern of soil water content (SWC) determines the success of vegetation restoration in semiand arid regions. The Qilian Mountains in China are in a semi-arid area where decades of environmental degradation prompted large-scale restoration efforts with a native constructive species Picea crassifolia . However, the relationships between SWC and landcover are not clear in this area, hindering woodland restoration. In this study, we determined spatial distribution and characteristics of SWC in the Qilian Mountains in four main types of landcover. Our results revealed that 1 . SWC decreased in the order of natural forest, brushland, grassland, planted forest, and mixed forest, but it was significantly different only in natural forest $(\mathrm{p}<0.05) ; 2$. planted forest exhibited a lower SWC at young ages (less than 50 a) than natural forest, brushland or grassland, and the ecohydrological effect of afforestation exhibited hysteresis at long time scales; 3. a variogram analysis and Kriging interception of the spatial pattern of SWC showed that shrubland and grassland exhibited superior adaptability to local SWC compared with afforestation. The differences in SWC among various landcover types indicated that strengthening the maintenance and protection of natural forests is more important for restoration efforts than afforestation; furthermore, in semi-arid regions, shrubs and grasses are more suitable for use in ecological restoration than forest plantations.
\end{abstract}

Keywords: Soil water content, Spatial heterogeneity, Semi-arid region, Plantation, Kriging interception

\title{
1. Introduction
}

Spatial distribution of surface soil water content (SWC) is significant to the interaction between vegetation and soil moisture in semi-arid and arid areas (Brocca et al., 2007; Zhao et al., 2020), and reveals how hydrological dynamics are linked to ecological patterns and processes (Grayson et al., 1998; Robinson et al., 2008; Seneviratne et al., 2010). In fact, the amount and spatial distribution of SWC directly determine the patterns and population abundance of vegetation (A et al., 2019; Brocca et al., 2010). In semi-arid regions, the presence and absence of seasonal vegetation showed highest correlation with SWC (Gomez-Plaza et al., 2000), while areas with little vegetation were mostly affected by local controls such as slope and soil texture (Gómez-Plaza et al., 2001).

The Qilian Mountains in northwestern China is an extensive area with semi- and arid climate. The area is also a source of numerous inland rivers which support extensive irrigated agriculture in the Hexi River Corridor. Several afforestation projects have been implemented in the area to conserve soil and water, control desertification, and to produce wood (Wang et al., 2010), P. crassifolia is the main constructive species in the Qilian Mountains (Zhao et al., 2011). Therefore, planting and management of P. crassifoflia forests is likely to have a profound impact on the stability and development of the Hexi River corridor ecosystem (Baroni et al., 2013; Vereecken et al., 2008) due to increased demands on the SWC.

The spatial pattern of SWC is driven by many environmental factors, including soil type, topography, vegetation, and the quantity of local precipitation (Brocca et al., 2007). Liu et al. (2013) analyzed vegetation patterns and hydraulic properties of surface soils in an alpine catchment, and showed that the surface SWC pattern was controlled mainly by terrain-related processes. In a loess hilly region of China, SWC determines a self-organized vegetation pattern in arid environments, while the reverse was not true and vegetation patterns did not greatly affect SWC (Sun et al., 2014).

At a small spatial scale, heterogeneity in land use, vegetation type, and soil characteristics are the dominant factors in SWC dynamics (Zhao et al., 2017; Zucco et al., 2014). SWC is also controlled by antecedent moisture conditions of the sampling plot (Famiglietti et al., 1998; Zhao et al., 2011; Zucco et al., 2014). Precipitation was the control factor in vegetation change in arid zones, and an observed decrease in SWC led to a reduction in evapotranspiration (Guan et al., 2020). According to Jian et al. (2015), plant water uptake in semi-arid regions occurs mostly through night-time root uptake and day-time evapotranspiration; this indicates that SWC in the main zone of plant root systems is critical to the physiological activities and growth of surface vegetation in water-limited ecosystems. Thus, SWC supply in arid regions is the main limiting factor for land-cover and vegetation succession, and any tradeoff or change in hydrological processes may cause a significant disturbance to the ecosystem and result in a new landscape pattern (Brocca et al., 
2007; Cosh et al., 2008; Sala et al., 2014; Wang et al., 1999; Wang et al., 2011).

Forest planting is extensive in China; it has been extensively promoted during the last 20 years with the "Grain for Green" projects which aimed to convert croplands to forests, shrublands and grasslands to prevent ecosystem degradation (Cao et al., 2011; Fu et al., 2011). Ecosystem restoration in the Qilian Mountains is reaching new levels with a plan for the "Qilian Mountain National Forest Park", in which 5.02 million ha are being restored (Liu et al., 2008; McVicar et al., 2010). However, limited information is available on the response of SWC to shifts in vegetation types in arid ecosystems, and, to date, the hydraulic interaction between planted forests and SWC is not clear. A greater understanding of this interaction is needed and of the spatial evolution of SWC under different landcover types to ensure success of ecosystem restoration.

Here, we used a geostatistical spatial analysis of the pattern of surface SWC in different-aged P. crassifolia forest, native grassland, shrubland, and mixed landcover in the region; here, grassland, shrubland and mixed landcover were considered to be the successive stages along the development of the local ecosystem into forestland.

We aimed to advance our understanding of forest plantation in arid areas by providing data support for regional forest-water relationship research. Our main objectives were to: (a) quantify the evolution trend of surface SWC during the early stages of plantation development, (b) characterize the spatial heterogeneity in SWC in reforested areas of different ages, and (c) determine the best sampling methods for SWC for spatial pattern analyses in semi- and arid regions.

\section{Methods}

\subsection{Site description}

The study was conducted in the Dahuang Mountain Forest Reserve $\left(100^{\circ} 22^{\prime}\right.$ E, 38deg43' N, Fig. 1) in the Qilian Mountains. The study area is located approximately $45 \mathrm{~km}$ southeast of Shandan County, Gansu Province, China, in the northern part of the Qilian Mountains in a typical arid area, with P. crassifolia as a dominant tree species. Several afforestation projects have been implemented in this area, providing a perfect opportunity to elucidate spatial patterns of SWC following a vegetation change. The climate is semiarid and cold temperate, with a mean annual temperature of 2.5 , and mean annual precipitation of $385 \mathrm{~mm}$ (for years 1994 to 2014); approximately $80 \%$ of the precipitation falls during the warmer months of June through September (He et al., 2019). Soils are gray cinnamon on shaded and semi-shaded slopes, and chestnut (Chinese soil taxonomy) on sunny slopes (Chen et al., 2016).

Forests are dominated by $P$. crassifolia, and are distributed on shaded and semi-shaded slopes; grasslands are primarily found on sunny and semi-sunny slopes, and shrubland is distributed in the transition between forest and grassland. Since the 1970s, most of the forest at low elevation had been cut down to satisfy an increasing demand for timber and crop production in the region. Dahuang Mountain has been included in Natural Forest Protection Projection (in response to deforestation-caused flooding) since 2001, and most of the grasslands on east- and west-facing slopes have been successively converted to $P$. crassfolia plantation forests, with an increase in the proportion of forest-grass cover of an average of $6.2 \%$ from 2000 to 2010 (Sun, 2020).

\subsection{Experimental design and sampling}

\subsubsection{Experimental plots}

Ten hillslope plots (sizes between 800-4000 $\mathrm{m}^{2}$, and elevation from $2595-2683 \mathrm{~m}$ ) were established along two orientations (horizontal or vertical axis) transect in the Dahuang Mountain Forest Reserve between July and August in 2014 (Fig. 2). Two plots were on the north-facing slope, and others on the west/east-facing slopes, and all of the plots were characterized by heterogeneity of land uses. Basic characteristics of the ten plots are shown in Table 1. The primary landcover types were grass, brush-grass, planted forest, planted-natural mixed forest, and natural forest, representing all stages of landcover changes during plantation restoration in this region. Plots along the horizontal axis $(\# 6, \# 7$ and $\# 8)$ were used to determine the relationship 
between landcover and SWC for which can exclude differences in SWC caused by slope position; plots along the vertical axis $(\# 1, \# 2, \# 3, \# 4, \# 5, \# 9$ and $\# 10)$ were used to analyze spatial heterogeneity of SWC and landcover types. Five spatial sampling intervals $(5,6,7,8$, and 10 meter) were used for the investigation, all sampling retained a consistent interval distance at each transect to satisfy the theoretical model of semivariance analysis. Four replicates of SWC records were taken at each sampling point, and the average value was taken for the point after the outliers were removed. In addition to supporting materials, the SWC survey, stand structure investigation, soil texture, and landcover species were also surveyed synchronously.

\subsubsection{Soil water content (SWC)}

Volumetric SWC was measured using time domain reflectometry (TDR) (IMKO, Germany) at $16 \mathrm{~cm}$ depth (after removing the surface litter layer). TDR probes were calibrated with SWC obtained gravimetrically (as theoretical values), and the calibration error between the value of the instrument and that of theoretical was $<2 \%$. We obtained 1920 field SWC records in the investigation. In order to minimize the impact of environmental factors (such as precipitation events) on surface SWC, there were at least 7 sunny days before and, so as to better reflect the interaction and hydrological connection between SWC and landcover types, and no precipitation during the study period.

\subsection{Statistical analysis}

\subsubsection{Statistical analysis}

We used SPSS 19.0 (SPSS Inc. software products, Chicago, USA) to distinguish differences in SWC among the tested landcover types. Before the semivariance analysis, all data were tested for normal distribution and distribution consistency across landcover types using One-Sample Kolmogorov-Smirnov Test in SPSS; details and statistical parameters are given in Table 2. The variability in SWC for each study plot or landcover was described by the mean, standard deviation, minimum, maximum, skewness and kurtosis. Regression analyses and graphs conducted using OriginPro 9.0 (OriginLab, USA), and data preprocessing was conducted in Microsoft Excel 2013.

\subsubsection{Geostatistical analysis}

Geostatistical analysis can help to quantify the spatial characteristics of SWC for each plot and to determine a potential spatial pattern using interpolation techniques based on the parameters of the analysis results. These techniques evaluate the semivariance $r(\mathrm{~h})$ for all possible pairs of nearby-sampled points based on the distance and the degree of autocorrelation among sampling points (Zhao et al., 2011).

Geostatistical analysis involves two main parts: (1) evaluation of the degree of autocorrelation among the measured points, (2) interpolation for similar points not actually sampled, based on the degree of autocorrelation encountered. The semivariance function $r(\mathrm{~h})$ was calculated using the following formula:

where $r(h)$ is the semivariance for interval distance class $h, h$ is the sampling interval in each plot, $z\left(x_{i}\right)$ is the measured sample value at point $x_{i}, z\left(x_{i+h}\right)$ is the sample value at point $x_{i+h}$, and $N(h)$ is the total number of sample pairs within the distance interval $h$. The shape of the resulting plot of $r(h)$ describes the degree of autocorrelation present.

Autocorrelation analysis and kriging interpolation was conducted with GS + 7.0 (GeoStatistics for the Environmental Sciences, GS+, Gamma Design Software, Plainwell, Michigan USA.). Three model parameters are needed for modeled variograms: (a) the separation distance over which spatial dependence is apparent (range, $A$ ), (b) the level of randomness (nugget variance, $C_{0}$ ), and (c) total variation present (sill, $C_{0}+C$ ), and then (d) $\mathrm{C} /\left(\mathrm{C}+\mathrm{C}_{\mathrm{o}}\right)$ defines the spatial dependence of SWC. $\mathrm{C} /(\mathrm{C}+\mathrm{Cdeg})>0.75$ indicates a strong spatial dependence relationship, and value between 0.25 and 0.75 means a moderate spatial dependence, with still lower values representing a lower degree of auto-correlation (Zimmermann et al., 2008; Zuo et al., 2008).

The nature of spatial variability in data can be depicted by the four variogram models including spherical, exponential, linear, and Gaussian (Isaaks et al., 1989; Webster et al., 1990). To evaluate the performance 
of the statistical model, we used RSS (Residual Sums of Squares), a measure of how well the model fits variogram data. This is one of sensitive and robust indexes, and RSS is also the parameter for the variogram model obtained by determining a combination of parameter values; thus, semivariogram model-fitting was performed based on the lowest RSS. In addition, regression and coefficient of determination $\left(\mathrm{r}^{2}\right)$ were used to indicate how well the model fits the variogram data.

\section{Results}

\subsection{SWC variability with landcover types}

SWC data collected from 10 sampling plots across different landcover types are shown in Fig. 3 and Table 2. Data for each plot conform to normal distribution, with the absolute value of Skewness andKurtosis of $<1$. There were some differences (from 9.01 to $16.55 \mathrm{~cm}^{3} \mathrm{~cm}^{-3}$ ) in surface SWC corresponding to various landcover types, but most were not significant. For example, brushland $\left(15.81 \mathrm{~cm}^{3} \mathrm{~cm}^{-3}\right)$ exhibited significant differences compared with planted forest $\left(12.28 \mathrm{~cm}^{3} \mathrm{~cm}^{-3}\right)$ and grassland $\left(13.30 \mathrm{~cm}^{3} \mathrm{~cm}^{-3}\right)$ (plot \#6 in Fig. 3 ), and grassland $\left(13.35 \mathrm{~cm}^{3} \mathrm{~cm}^{-3}\right)$ also exhibited unnoteworthy compared with planted and mixed forests $\left(10.53 \mathrm{~cm}^{3} \mathrm{~cm}^{-3}\right)$ (plot $\# 9$ in Fig. 3). The differences between natural $\left(16.5 \mathrm{~cm}^{3} \mathrm{~cm}^{-3}\right)$ and planted forests $\left(11.82 \mathrm{~cm}^{3} \mathrm{~cm}^{-3}\right.$ ) were notable (mean value between plot \#10 and plot $\# 2$ ).

To further quantify SWC differences among the landcover types, SWC was summarized using SPSS by landcover type (Fig. 4). Results showed a decreasing trend from natural forest, brushland, grassland and planted forest to mixed forest, representing changes in SWC over several decades of plantation succession in this semi- and arid region. SWC in planted forest and mixed planted forest was lower than that in the brush and grass areas, with the only significant difference found between the natural forest and other landcover types.

Furthermore, standard deviations in natural forest (plot \#10) and planted forest (plot \#1) were 6.16 $\mathrm{cm}^{3} \mathrm{~cm}^{-3}$ and $3.5 \mathrm{~cm}^{3} \mathrm{~cm}^{-3}$, respectively; while in brushland and grassland (plot $\# 8$ and $\# 3$ ), they were $1.18 \mathrm{~cm}^{3} \mathrm{~cm}^{-3}$ and $2.62 \mathrm{~cm}^{3} \mathrm{~cm}^{-3}$, respectively (Table 2). A larger standard deviation indicated that the forest had greater water storage capacity compared to other two landcover types.

\subsection{SWC semivariance characteristics of sampling plots}

We used Variogram analysis and Kriging interception to characterize and generate spatial structures of soil moisture for each plot area (Table 3). RSS for most plot areas was $<1$ (with an average value of 0.23 for plots \#2 and \#7), indicating a clear spatial auto-correlation relationship among data distribution in their effective ranges. Further, the models which we used for semivariance analysis were appropriate and the parameter combination for each fitting function model can be used for explanation of the spatial pattern in the study plots. $R S S$ in plot \#1 was 12.9 suggesting that the model used for plot \#1 was not as fitting as theoretically needed, and the interception map should be carefully considered in the following analysis.

We used the Gaussian model for plot $\# 3$, spherical for plots $\# 2, \# 5$, \#6 and \#10, and exponential for plots $\# 4, \# 7$ and $\# 9$, indicating that the fitting model was robust and interpolation results were based on a function that can represent the actual spatial pattern of SWC. The optimal function was linear for plot \#1 and \#8 which indicated that the model was not as ideal as the $R S S$ showed, and that may be a limitation due to the size of the dataset. A spatial correlation of $<0.5$ between SWC in plot \#1 and \#8 indicated that there was no spatial correlation, closely with what was reflected by RSS (Yang et al., 2017). Other sampling plots showed a strong spatial auto-correlation, indicating that parameters based on the models can be used for spatial interpolation of SWC at each sampling plot.

\subsection{Kriging interpolation of SWC}

P. crassifolia is a shallow-rooted tree species with roots distributed mainly in the first $30 \mathrm{~cm}$ below the ground surface (Chen et al., 2016) and, where also accounts for 40 to $60 \%$ of the total active profile moisture storage in a temperate climate region (Western et al., 1999). The results of this study showed the spatial pattern of SWC in surface soil (especially depths shallower than $20 \mathrm{~cm}$ ). Based on the simulation function 
for each plot, local Kriging interpolation was used for the spatial simulation of SWC (Fig. 5). The resulting spatial map of SWC was based on actual field values, and on the knowledge about the underlying spatial relationship obtained from sampling values.

SWC did not exhibit a consistent spatial pattern along the slope in the planted forest (plot \#2) or in the natural forest area (plot \#10), which suggest that the vertical axis spatial pattern of SWC in this waterlimited ecosystem was not controlled by the position of slope. These results differed from those of (Brocca et al., 2010; Vereecken et al., 2014), who reported that SWC depended on water transport via subsurface lateral flow from the upper slope to the toe when water was in sufficient supply. SWC along the horizontal axis exhibited a significant decreasing trend from shrubland to grassland or forestland (Fig. 3 and Fig. 5), indicating that shrubland had a superior soil and water conservation capacity in this water-limited area.

\subsection{The number of required samples (NRS) for SWC}

To obtain the minimum NRS to determine mean SWC in this semi- and arid region, a bootstrap resample of several plots had been simulated using Matlab script. Regardless of the initial value, the mean quickly converged to a stable value as the sample number increased with step sampling (Fig. 6a). To qualitatively determine the threshold of function-shifting, the first derivative of each fitting function was calculated in Fig. 6b. Two curve inflection points (the derivative was equal to +-1 and +-0.58 , with corresponding slopes of the fitting curve of $45^{\circ}$ and $30^{\circ}$ ) were marked on the graph, and four thresholds were found in this study.

\section{Discussion}

\subsection{SWC variability in different landcover types}

In general, amounts of mean annual precipitation determine the type and spatial pattern of dominant landcover in an ecosystem (Liu et al., 2020; Sun et al., 2014); however, human activities shift the rate and the magnitude of this relationship, particularly with large-scale programs such as "Grain for Green" in China (Cao, 2008; Cao et al., 2011). New landcover types change the water cycle from the land surface to the atmosphere by abiotic evaporation and biotic transpiration; with a complex hydraulic interaction between landcover and the environment, a new trade-off forms gradually and this change produces irreversible impacts to the local people's livelihood (Liu et al., 2020).

SWC in this study decreased in the following order: natural forest, brushland, grassland, planted forest, and mixed forest, with SWC in natural forest differing significantly from that in the other vegetation types $(\mathrm{p}<0.05)$ (Fig. 4). Furthermore, SWC in planted and mixed forests years decreased with age in this study, likely leading to a negative feedback to the water circulation processes in the ecosystem; these results were consistent with those of previous studies (Wang et al., 2011; Zhu et al., 2017), and may be illustrative of the repetitive degradation of the planted area within the past 20 years (A et al., 2019; He et al., 2007; Jia et al., 2017; Muneepeerakul et al., 2011; Sun et al., 2014). In the early stages of plantation establishment, soil moisture formed a new trade-off between the new vegetation cover and precipitation, and then a relatively stable water cycle was gradually established (Fu et al., 2003; Gomez-Plaza et al., 2001; Sun et al., 2014). It appears that forestland in arid regions can accumulate soil moisture when vegetation pattern is fully mature many years after planting. These findings highlight ecological efficiency of afforestation with hysteresis over long-time scales (Guan et al., 2020; Jia et al., 2017).

Topography is another notable source of SWC variability (Famiglietti et al., 1998; Fu et al., 2003). However, in this study spatial pattern of SWC showed along slope position SWC did not exhibit a significant declining trend from the top to the toe of slope in this study (plot \#9 in Fig. 3 and Fig. 5). These characteristics could generally be explained by $-14.3 \%$ runoff depth (forests decreased net water yield) and a mean annual precipitation of $374.1 \mathrm{~mm}$ in the Pailugou catchment (adjacent to this study area) in the Qilian mountains (He et al., 2012) indicating that interflow along the subsurface in this region cannot determine a self-organized vegetation pattern, as reported in the loess hilly region of China by Sun et al. (2014). The terrain-related processes may be the main environmental factor affecting the spatial pattern of vegetation during wet periods (Grayson et al., 1997; Western et al., 1999). 


\subsection{Spatial pattern and heterogeneity of SWC across succession stages of a planted forest}

As a spatial auto-correlation indicator, $\mathrm{C} /(\mathrm{C}+\mathrm{Cdeg})$ of $>0.75$ for most plots indicated a consistent spatial pattern of SWC among the sampling plots (Table 3). Auto-correlation distance $(A)$ of SWC occurred with non-homogeneity in this study, in which, forest and mixed forest showed a broader range compared with grass and shrubland $(A$ in plot $\# 3$ was $4.3 \mathrm{~m}$ ) in Table 3 . Additionally, $A$ for planted or mixed forest was still larger than that for natural forest area; these results indicated that SWC was not as stable elsewhere as it was in natural land cover in the early few decades of growth of a planted forest (Jia et al., 2017; Jia et al., 2006; Zhang et al., 2016). Furthermore, RSS for the fitting models was close to 0, which indicated that a sound spatial dependence was found in the geostatistical analysis for our sampling plots; this was mainly related to the coincident transpiration and transformation of the soil moisture across land cover types (Qiu et al., 2001; Yang et al., 2017).

Interception maps of SWC for the survey plots outline the spatial pattern of SWC in a more intuitive way (Webster et al., 1990). The mixed plots (\#6, \#7 and \#9 in Fig. 5) showed a strong auto-correlation; extremely similar continuity characteristics of SWC suggest that SWC in this region was mainly controlled by the frequency and magnitude of precipitation events (Fu et al., 2003; Qiu et al., 2001; Sun et al., 2016), and the landcover type played a secondary role (Grayson et al., 1997). Similar results were also demonstrated by Liu et al. (2020), who found that transpiration and evapotranspiration in boreal forests depend mainly on precipitation patterns.

\subsection{Sampling SWC in semi- and arid regions}

Sampling strategies may need to be adjusted to determine accurate areal SWC at catchment-wide scale (Grayson et al., 1998), and the interval of sampling is a critical factor which will determine the total number of samples and the cost of the experiment. According to Manfreda et al. (2006), NRS is a control factor in estimation of SWC variance, especially for soils with shallow-rooted vegetation; this is because the number of field samples must be large enough to obtain true values which are distributed close to the average for the study (A et al., 2019; Brocca et al., 2007; Brocca et al., 2012). To obtain the minimum NRS which can ensure measurement accuracy, we randomly resampled the records of planted forest with an incremental step method (bootstrap method in Fig. 6a), with the first derivative of the fitting curve in Fig. 6b ranging from +-1 to +-0.58 , and the number of required samples ranging from 5 to 9 (marked with L1 and U1) and 20 to 23 (marked with L2 and U2); the results suggest that $\sim 20$ sampling points with a sampling space of 5 to 10 meters in the planted forest could yield a representative SWC value in arid regions (Entekhabi et al., 1994; Vinnikov et al., 1999). However, this experimental method may not be appropriate for a large area especially in regions with frequent rainfall (Brocca et al., 2012).

\section{Conclusions}

In this study, we analyzed SWC variability with landcover types, and semivariance characteristics and spatial interpolation results using a geostatistical method in 10 survey plots. Kriging interception was conducted based on variogram analysis to characterize the spatial structure of SWC in each plot. SWC declined from natural forest, brushland, grassland, planted forest and mixed forest, whereas non-significant tendency was found alongside the vertical axes of slope-side among the landcover types. Results of this study indicated that planted and mixed forests, aged between 30 and 50 years, decreased SWC compared with natural forest or shrubland in semi- and arid regions. We propose that the vegetation used in restoration projects needs to be matched with the level of local mean annual precipitation.

\section{Acknowledgements}

This study was funded by the National Natural Sciences Foundation of China (41901050, 41901044, and 41621001), Strategic Priority Program of the Chinese Academy of Sciences, Grant/Award Number: XDA23060301,Key Program of the Chinese Academy of Sciences, Grant/Award Number: QYZDJ-SSWDQC040. Furthermore, we would like to thank Dr. Kathryn Piatek for her suggestions and editorial assistance in writing this article. 


\section{References:}

A, Y., Wang, G., Liu, T., Xue, B., \& Kuczera, G.Spatial variation of correlations between vertical soil water and evapotranspiration and their controlling factors in a semi-arid region,Journal of Hydrology, 2019, 574, 53-63.

Baroni, G., Ortuani, B., Facchi, A., \& Gandolfi, C.The role of vegetation and soil properties on the spatiotemporal variability of the surface soil moisture in a maize-cropped field,Journal of Hydrology, 2013, 489, 148-159.

Brocca, L., Melone, F., Moramarco, T., \& Morbidelli, R.Spatial-temporal variability of soil moisture and its estimation across scales, Water Resources Research, 2010, 46.

Brocca, L., Morbidelli, R., Melone, F., \& Moramarco, T.Soil moisture spatial variability in experimental areas of central Italy,Journal of Hydrology, 2007, 333, 356-373.

Brocca, L., Tullo, T., Melone, F., Moramarco, T., \& Morbidelli, R.Catchment scale soil moisture spatialtemporal variability,Journal of Hydrology, 2012, 422, 63-75.

Cao, S.Why large-scale afforestation efforts in China have failed to solve the desertification problem,Environmental Science \& Technology, 2008, 42(6), 1826-1831.

Cao, S. X., Chen, L., Shankman, D., Wang, C. M., Wang, X. B., \& Zhang, H.Excessive reliance on afforestation in China's arid and semi-arid regions: Lessons in ecological restoration.[Article],Earth-Science Reviews, 2011, 104(4), 240-245.

Chen, L., He, Z., Zhu, X., Du, J., Yang, J., \& Li, J.Impacts of afforestation on plant diversity, soil properties, and soil organic carbon storage in a semi-arid grassland of northwestern China,Catena, 2016, 147, 299-307.

Cosh, M. H., Jackson, T. J., Moran, S., \& Bindlish, R.Temporal persistence and stability of surface soil moisture in a semi-arid watershed,Remote Sensing of Environment, 2008, 112(2), 304-313.

Entekhabi, D., \& Rodriguez-Iturbe, I.Analytical framework for the characterization of the space-time variability of soil moisture,Advances in Water Resources, 1994, 17(1), 35-45.

Famiglietti, J. S., Rudnicki, J. W., \& Rodell, M.Variability in surface moisture content along a hillslope transect: Rattlesnake Hill, Texas,Journal of Hydrology, 1998, 210(1), 259-281.

Fu, B., Liu, Y., Lu, Y., He, C., Zeng, Y., \& Wu, B.Assessing the soil erosion control service of ecosystems change in the Loess Plateau of China,Ecological Complexity, 2011, 8(4), 284-293.

Fu, B., Wang, J., Chen, L., \& Qiu, Y.The effects of land use on soil moisture variation in the Danangou catchment of the Loess Plateau, China,Catena, 2003, 54(1), 197-213.

Gomez-Plaza, A., Alvarez-Rogel, J., Albaladejo, J., \& Castillo, V. M.Spatial patterns and temporal stability of soil moisture across a range of scales in a semi-arid environment,Hydrological Processes, 2000, 14(7), 1261-1277.

Gomez-Plaza, A., Martınez-Mena, M., Albaladejo, J., \& Castillo, V. M.Factors regulating spatial distribution of soil water content in small semiarid catchments,Journal of Hydrology, 2001, 253(1), 211-226.

Grayson, R. B., \& Western, A. W.Towards areal estimation of soil water content from point measurements: time and space stability of mean response,Journal of Hydrology, 1998, 207(1), 68-82.

Grayson, R. B., Western, A. W., Chiew, F. H. S., \& Blöschl, G.Preferred states in spatial soil moisture patterns: Local and nonlocal controls.[https://doi.org/10.1029/97WR02174], WaterResources Research, 1997, 33(12), 2897-2908.

Guan, Y., Lu, H., Yin, C., Xue, Y., Jiang, Y., Kang, Y., He, L., \& Heiskanen, J.Vegetation response to climate zone dynamics and its impacts on surface soil water content and albedo in China,Science of The 
Total Environment, 2020, 747, 141537.

He, Z., Zhao, M., Zhu, X., Du, J., Chen, L., Lin, P., \& Li, J.Temporal stability of soil water storage in multiple soil layers in high-elevation forests,Journal of Hydrology, 2019, 569, 532-545.

He, Z., Zhao, W., \& Chang, X.The modifiable areal unit problem of spatial heterogeneity of plant community in the transitional zone between oasis and desert using semivariance analysis.[Article],Landscape Ecology, 2007, 22(1), 95-104.

He, Z., Zhao, W., Liu, H., \& Tang, Z.Effect of forest on annual water yield in the mountains of an arid inland river basin: a case study in the Pailugou catchment on northwestern China's Qilian Mountains,Hydrological Processes, 2012, 26(4), 613-621.

Isaaks, E. H., \& Srivastava, R. M. (1989). An introduction to applied geostatistics (pp. 520-561). New York: Oxford University Press.

Jia, X., Shao, M. a., Zhu, Y., \& Luo, Y.Soil moisture decline due to afforestation across the Loess Plateau, China,Journal of Hydrology, 2017, 546, 113-122.

Jia, Y., Li, F., \& Wang, X.Soil quality responses to alfalfa watered with a field micro-catchment technique in the Loess Plateau of China,Field Crops Research, 2006, 95, 64-74.

Jian, S., Zhao, C., Fang, S., \& Yu, K.Effects of different vegetation restoration on soil water storage and water balance in the Chinese Loess Plateau,Agricultural and Forest Meteorology, 2015, 206, 85-96.

Liu, H., Zhao, W., \& He, Z.Self-organized vegetation patterning effects on surface soil hydraulic conductivity: A case study in the Qilian Mountains, China,Geoderma, 2013, 192, 362-367.

Liu, J., Cheng, F., Munger, W., Jiang, P., Whitby, T. G., Chen, S., Ji, W. W., \& Man, X.Precipitation extremes influence patterns and partitioning of evapotranspiration and transpiration in a deciduous boreal larch forest,Agricultural and Forest Meteorology, 2020, 287, 107936.

Liu, J., \& Diamond, J.Revolutionizing China's Environmental Protection,Science, 2008, 319(5859), 37.

Manfreda, S., \& Rodríguez-Iturbe, I.On the spatial and temporal sampling of soil moisture fields, Water Resources Research, 2006, 42(5).

McVicar, T. R., VanNielb, T. G., Li, L. T., Wen, Z. M., Yang, Q. K., Li, R., \& Jiao, F.Parsimoniously modelling perennial vegetation suitability and identifying priority areas to support China's re-vegetation program in the Loess Plateau: Matching model complexity to data availability,Forest Ecology and Management, 2010, $259(7), 1277-1290$.

Muneepeerakul, C. P., Muneepeerakul, R., Miralles-Wilhelm, F., Rinaldo, A., \& Rodriguez-Iturbe, I.Dynamics of wetland vegetation under multiple stresses: a case study of changes in sawgrass trait, structure, and productivity under coupled plant-soil- microbe dynamics,Ecohydrology, 2011, 4(6), 757-790.

Qiu, Y., Fu, B., Wang, J., \& Chen, L.Soil moisture variation in relation to topography and land use in a hillslope catchment of the Loess Plateau, China,Journal of Hydrology, 2001, 240(3), 243-263.

Robinson, D. A., Campbell, C. S., Hopmans, J. W., Hornbuckle, B. K., Jones, S. B., Knight, R., Ogden, F., Selker, J., \& Wendroth, O.Soil moisture measurement for ecological and hydrological watershed-scale observatories: A review,Vadose Zone Journal, 2008, 7(1), 358-389.

Sala, O. E., \& Maestre, F. T.Grass-woodland transitions: determinants and consequences for ecosystem functioning and provisioning of services,Journal of Ecology, 2014, 102(6), 1357-1362.

Seneviratne, S. I., Corti, T., Davin, E. L., Hirschi, M., Jaeger, E. B., Lehner, I., Orlowsky, B., \& Teuling, A. J.Investigating soil moisture-climate interactions in a changing climate: A review,Earth-Science Reviews, 2010, 99(3-4), 125-161. 
Sun, F., Lu, Y., Fu, B., Ma, Z., \& Yao, X.Spatial explicit soil moisture analysis: pattern and its stability at small catchment scale in the loess hilly region of China,Hydrological Processes, 2014, 28(13), 4091-4109.

Sun, W.Effect of closing the land for reforestation in ecological degraded area of Dahuang Mountain,Protection Forest Science and Technology, 2020, (3), 43-45.

Sun, Z., Wang, Q., Batkhishig, O., \& Ouyang, Z.Relationship between Evapotranspiration and Land Surface Temperature under Energy- and Water-Limited Conditions in Dry and Cold Climates,Advances in Meteorology, 2016, 2016, 1835487.

Vereecken, H., Huisman, J. A., Bogena, H., Vanderborght, J., Vrugt, J. A., \& Hopmans, J. W.On the value of soil moisture measurements in vadose zone hydrology: A review, Water Resources Research, 2008, 44.

Vereecken, H., Huisman, J. A., Pachepsky, Y., Montzka, C., van der Kruk, J., Bogena, H., Weihermueller, L., Herbst, M., Martinez, G., \& Vanderborght, J.On the spatio-temporal dynamics of soil moisture at the field scale,Journal of Hydrology, 2014, 516, 76-96.

Vinnikov, K. Y., Robock, A., Qiu, S., \& Entin, J. K.Optimal design of surface networks for observation of soil moisture,Journal of Geophysical Research: Atmospheres, 1999, 104(D 16), 19,743-719,749.

Wang, G., \& Cheng, G.Water resource development and its influence on the environment in arid areas of China-the case of the Hei River basin,Journal of Arid Environments, 1999, 43(2), 121-131.

Wang, X. M., Zhang, C. X., Hasi, E., \& Dong, Z. B.Has the Three Norths Forest Shelterbelt Program solved the desertification and dust storm problems in arid and semiarid China?,Journal of Arid Environments, 2010, 74(1), 13-22.

Wang, Y., Shao, M. a., Zhu, Y., \& Liu, Z.Impacts of land use and plant characteristics on dried soil layers in different climatic regions on the Loess Plateau of China,Agricultural and Forest Meteorology, 2011, 151(4), 437-448.

Webster, R., \& Oliver, M. A. (1990). Statistical methods in soil and land resource survey. New York: Oxford University Press.

Western, A. W., Grayson, R. B., Bloschl, G., Willgoose, G. R., \& McMahon, T. A.Observed spatial organization of soil moisture and its relation to terrain indices, Water Resources Research, 1999, 35(3), 797-810.

Yang, Y., Dou, Y., Liu, D., \& An, S.Spatial pattern and heterogeneity of soil moisture along a transect in a small catchment on the Loess Plateau,Journal of Hydrology, 2017, 550, 466-477.

Zhang, X., Zhao, W., Liu, Y., Fang, X., \& Feng, Q.The relationships between grasslands and soil moisture on the Loess Plateau of China: A review,Catena, 2016, 145, 56-67.

Zhao, C., Jia, X., Zhu, Y., \& Shao, M. a.Long-term temporal variations of soil water content under different vegetation types in the Loess Plateau, China,Catena, 2017, 158, 55-62.

Zhao, Y., Peth, S., Hallett, P., Wang, X. Y., Giese, M., Gao, Y. Z., \& Horn, R.Factors controlling the spatial patterns of soil moisture in a grazed semi-arid steppe investigated by multivariate geostatistics,Ecohydrology, 2011, 4(1), 36-48.

Zhao, Z., Shen, Y., Wang, Q., \& Jiang, R.The temporal stability of soil moisture spatial pattern and its influencing factors in rocky environments, Catena, 2020, 187, 104418.

Zhu, X., He, Z., Du, J., Chen, L., Lin, P., \& Li, J.Temporal variability in soil moisture after thinning in semi-arid Picea crassifolia plantations in northwestern China,Forest Ecology and Management, 2017, 401, 273-285.

Zimmermann, B., \& Elsenbeer, H.Spatial and temporal variability of soil saturated hydraulic conductivity in gradients of disturbance,Journal of Hydrology, 2008, 361(1-2), 78-95. 
Zucco, G., Brocca, L., Moramarco, T., \& Morbidelli, R.Influence of land use on soil moisture spatial-temporal variability and monitoring,Journal of Hydrology, 2014, 516(6), 193-199.

Zuo, X., Zhao, H., Zhao, X., Zhang, T., Guo, Y., Wang, S., \& Drake, S.Spatial pattern and heterogeneity of soil properties in sand dunes under grazing and restoration in Horqin Sandy Land, Northern China,Soil and Tillage Research, 2008, 99(2), 202-212.

\section{Hosted file}

Tables.docx available at https://authorea.com/users/457573/articles/554311-spatialheterogeneity-of-soil-water-content-on-surface-land-following-reforestation-in-a-semiarid-region

\section{Hosted file}

Figs.docx available at https://authorea.com/users/457573/articles/554311-spatialheterogeneity-of-soil-water-content-on-surface-land-following-reforestation-in-a-semiarid-region 